\title{
PRDX1 is essential for the viability and maintenance of reactive oxygen species in chicken DT40
}

\author{
Takahito Moriwaki $^{1 \dagger}$, Akari Yoshimura ${ }^{2 \dagger}$, Yuki Tamari ${ }^{3}$, Hiroyuki Sasanuma ${ }^{4}$, Shunichi Takeda ${ }^{4}$, Masayuki Seki ${ }^{2}$ and \\ Keizo Tano ${ }^{5^{*}}$ (D)
}

\begin{abstract}
Background: Peroxiredoxin 1 (PRDX1) is a member of a ubiquitous family of thiol peroxidases that catalyze the reduction of peroxides, including hydrogen peroxide. It functions as an antioxidant enzyme, similar to catalase and glutathione peroxidase. PRDX1 was recently shown act as a sensor of reactive oxygen species (ROS) and play a role in ROS-dependent intracellular signaling pathways. To investigate its physiological functions, PRDX1 was conditionally disrupted in chicken DT40 cells in the present study.

Results: The depletion of PRDX1 resulted in cell death with increased levels of intracellular ROS. PRDX1-depleted cells did not show the accumulation of chromosomal breaks or sister chromatid exchange (SCE). These results suggest that cell death in PRDX1-depleted cells was not due to DNA damage. 2-Mercaptoethanol protected against cell death in PRDX1-depleted cells and also suppressed elevations in ROS.

Conclusions: PRDX1 is essential in chicken DT40 cells and plays an important role in maintaining intracellular ROS homeostasis (or in the fine-tuning of cellular ROS levels). Cells deficient in PRDX1 may be used as an endogenously deregulated ROS model to elucidate the physiological roles of ROS in maintaining proper cell growth.
\end{abstract}

\section{Introduction}

Peroxiredoxins (PRDXs) are highly ubiquitous cysteinedependent peroxidases that remove peroxides, including hydrogen peroxide, organic hydroperoxides, and peroxynitrite [1-4]. In most vertebrates, the PRDX family comprises 6 isoforms (PRDX1-6), which are classified into two subfamilies, 1-Cys and 2-Cys, based on the number of conserved active cysteine residues [5, 6]. PRDX1 is a member of the 2-Cys PRDX1 subfamily and the oxidation of two cysteines is required to activate its enzymatic activity [7]. One cysteine residue at the $\mathrm{N}$ terminus of PRDX1 is oxidized to detoxify peroxides through

\footnotetext{
* Correspondence: tano.keizo.y90@kyoto-u.jp

${ }^{\dagger}$ Takahito Moriwaki and Akari Yoshimura contributed equally to this work. ${ }^{5}$ Department of Biological Sciences, Graduate School of Science, Osaka Prefecture University, 1-1 Gakuen-cho, Naka-ku, Sakai, Osaka 599-8531, Japan Full list of author information is available at the end of the article
}

intermolecular disulfide formation with the other cysteine residue at the $\mathrm{C}$ terminus $[7,8]$. PRDX1 localizes to the cytosol and is abundant in cultured mammalian cells [9]. In addition to its antioxidant enzymatic activity, various functions have been reported for PRDX1. It has been shown to play roles in tumor suppression [10-13], apoptosis [14-16], and molecular chaperoning [17, 18]. A previous study demonstrated that PRDX1 knockout mice were viable and fertile, but developed severe hemolytic anemia and several malignant cancers, which shortened their life span [10]. Another PRDX1 knockout mouse study showed elevated nuclear reactive oxygen species (ROS) levels in primary tissues isolated from these mice with increased DNA damage and tumor susceptibility [12]. However, the physiological role of PRDX1 in the oxidization-reduction balance remains unclear. 
We have been investigating the physiological roles of ROS by targeting genes involved in ROS scavenging using a reverse genetics strategy in chicken DT40 cell lines derived from an avian leukosis virus (ALV)-induced bursal lymphoma. Superoxide dismutase 1 (SOD1) and 2 (SOD2) were systematically disrupted to generate conditional mutant cells in which the human SOD1 or SOD2 transgene was expressed under the control of a tetracycline-inducible promoter [19-21]. These cell lines enabled us to eliminate the exogenous effects of ROS and characterize phenotypes caused by endogenously disturbed ROS levels. As a part of this strategy, we generated PRDX1 conditional mutant cells in which the expression of Gallus Gallus domesticus PRDX1(ggdPRDX1) may be turned off by a treatment with doxycycline (DOX) and examined cellular responses immediately after the depletion of PRDX1. The results obtained demonstrated that the depletion of PRDX1 resulted in cell death with increases in total ROS levels and genome integrity was maintained. The lethality of PRDX1-deficient cells was completely suppressed by the addition of a reductant, 2-mercaptoethanol. Based on the present results, the maintenance of finely tuned cellular ROS levels, particularly hydrogen peroxide, by PRDX1 appears to be a crucial factor for normal cell metabolism.

\section{Materials and methods}

\section{Cell culture}

Cells were cultured in RPMI 1640 supplemented with $10 \%$ fetal bovine serum and $1 \%$ chicken serum at $39{ }^{\circ} \mathrm{C}$ under $5 \% \mathrm{CO}_{2}$ without a reductant for a normal culture [22]. To investigate the effects of various antioxidants on cell viability, cells were cultured in the presence or absence of DOX for the indicated periods and then treated with antioxidants, $200 \mu \mathrm{M}$ ascorbic acid phosphate magnesium salt (Wako, Osaka, Japan), $5 \mathrm{mM} \mathrm{N}$-acetyl-L-cysteine (NAC, Wako, Osaka, Japan), $250 \mu \mathrm{M}$ 1,2-dihydroxy-3,5-benzenedisulfonic acid (Tiron, Sigma-Aldrich), or $50 \mu \mathrm{M} 2$ mercaptoethanol (Et-SH, Sigma-Aldrich). Growth curves were generated as previously described [19-21].

\section{Cell lines used in this study}

The SOD $1^{-/-}+h S O D 1$ cell line was generated as described [20]. Briefly, since the knockout of the SOD1 gene in DT40 is lethal, a conditional SOD1 knockout with a human SOD1 gene under the control of a tetracycline-inducible promoter was generated (the SOD $1^{-1-}+h S O D 1$ cell line). A conditional PRDX1knockout cell line with a $g g d P R D X 1$ gene was generated in this study.

\section{Plasmid construction}

DNA containing exons 2-4 of PRDX1 was obtained by PCR from DT40 genomic DNA using the Easy-DNA Kit
(Invitrogen, Carlsbad, California, USA) and Ex-Taq polymerase (Takara Bio Inc., Otsu, Shiga, Japan). The chicken targeting constructs for $P R D X 1, P R D X 1$-blasticidin and $P R D X 1$-ecogpt, were generated by replacing exons 2-4 with the blasticidin or ecogpt selection marker cassette. To construct an expression plasmid carrying $g g d P R D X 1 \mathrm{cDNA}(g g d P R D X 1 c D N A)$ with the tetoff promoter, $g g d P R D X 1 \mathrm{cDNA}$ was obtained by reverse transcription-PCR (RT-PCR) using mRNA from DT40 cells using SuperScript III Reverse Transcriptase (Invitrogen) and Flag-tagged PRDX1 cDNA inserted into the pUHG 10-3 vector.

\section{Measurement of intracellular ROS}

Intracellular ROS levels were measured using $2^{\prime}, 7^{\prime}$ dichlorodihydrofluorescein diacetate (DCFH-DA; Molecular Probes, USA). Intracellular peroxide-dependent oxidation converts DCFH-DA to the fluorescent compound $2^{\prime}, 7^{\prime}$-dichlorofluorescein (DCF), as previously described [23]. After washing antioxidant treated or untreated cells with PBS, cells were incubated with DCFADA $(20 \mu \mathrm{M})$ at $37^{\circ} \mathrm{C}$ for $30 \mathrm{~min}$, harvested, and resuspended in $50 \mathrm{mM}$ HEPES buffer ( $5 \mathrm{mM}$ HEPES, pH 7.4, $5 \mathrm{mM} \mathrm{KCl}, 140 \mathrm{mM} \mathrm{NaCl}, 2 \mathrm{mM} \mathrm{CaCl}, 1 \mathrm{mM} \mathrm{MgCl}_{2}$, and $10 \mathrm{mM}$ glucose). Fluorescence intensity was assessed using FACScan (Becton Dickinson, Franklin Lakes, NJ) with excitation at $485 \mathrm{~nm}$ and emission at $530 \mathrm{~nm}$.

\section{Measurement of intracellular superoxide levels}

Intracellular superoxide levels were detected using BESSo-AM (Wako Pure Chemical Industries Ltd.), a highly specific fluorescent probe for superoxide [24]. Briefly, cells were treated with $5 \mu \mathrm{M}$ BES-So-AM for $20 \mathrm{~min}$. After washing twice with PBS, cells were suspended in PBS, and fluorescent intensity was measured using FACScan.

\section{Measurement of sister chromatid exchange (SCE)}

An analysis of sister chromatid exchange was performed as previously described $[19,20]$. Briefly, cells were cultured for two rounds of the cell cycle in medium containing $10 \mu \mathrm{M} \mathrm{BrdU}$ and $0.1 \mu \mathrm{g} / \mathrm{ml}$ colcemid for $2 \mathrm{~h}$. Cells were harvested and treated with $75 \mathrm{mM} \mathrm{KCl}$ at room temperature for $18 \mathrm{~min}$ and fixed with methanolacetic acid (3:1) for $30 \mathrm{~min}$. The cell suspension was then dropped onto wet glass slides. After air drying, cells on the slides were incubated with Hoechst 33258 in phosphate buffer ( $\mathrm{pH}$ 6.8) and rinsed with Macllavine solution. After cells had been exposed to black light $(\lambda=352$ $\mathrm{nm}$ ) for $20 \mathrm{~min}$, they were stained with 3\% Giemsa solution for $20 \mathrm{~min}$. 


\section{Analysis of chromosomal aberrations}

An analysis of chromosomal aberrations was performed as described previously [22]. Briefly, cells were treated for $2.5 \mathrm{~h}$ with medium containing $0.1 \mu \mathrm{g} / \mathrm{ml}$ colcemid (Gibco). Harvested cells were incubated in $1 \mathrm{ml}$ of 75 $\mathrm{mM} \mathrm{KCl}$ at room temperature for $15 \mathrm{~min}$ and fixed in 5 $\mathrm{ml}$ of a freshly prepared 3:1 mixture of methanol-acetic acid. The cell suspension was dropped onto a slide, and after air drying, cells were stained with 5\% Giemsa solution ( $\mathrm{pH}$ 6.4, Nacalai Tesque, Japan) for $8 \mathrm{~min}$. Data are shown as macro chromosomal aberrations per 50 metaphase spreads.

\section{Statistical analysis}

Three independent experiments were performed for each data set unless stated otherwise. The results obtained are expressed as the mean \pm SD unless stated otherwise. The significance of differences was examined using the Student's $t$-test, and $p$ values of $<0.05$ were considered to be significant. A multiplecomparison one-way ANOVA was performed using Tukey's test.

\section{Results}

Generation of conditional PRDX1 knockout cells

To investigate the physiological roles of PRDX1 without exogenous oxidative stress, we generated conditional prdx 1 cells in which the ggdPRDX1 transgene was expressed under the control of the tetracycline-inducible promoter. The expression of the PRDX1 transgene was switched off by the addition of DOX, which resulted in the complete depletion of exogenous PRDX1 proteins. The strategy of generating conditional PRDX1-deficient cells is shown in Fig. 1A. DT40 wild-type cells were transfected with a plasmid expressing FLAG-tagged ggdPRDX1 cDNA driven by the tet-off promoter. PRDX1 genes were then disrupted as shown in Fig. 1B. Disruption was confirmed by Southern blotting (data not shown). The suppressed expression of the PRDX1 gene and the depletion of the PRDX1 protein were confirmed by RT-PCR and Western blotting, respectively. The transcript and protein levels of PRDX1 both disappeared 96 $\mathrm{h}$ after the addition of DOX (Fig. $1 \mathrm{C}$ and D). These cells enabled us to characterize cellular responses caused by the depletion of PRDX1 without exogenous oxidative stress.
(A)

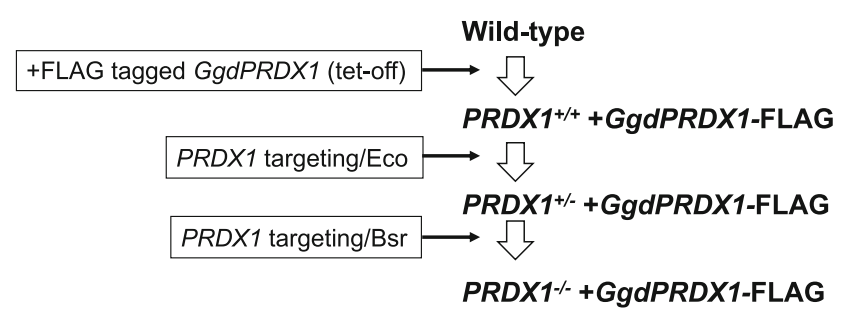

(C)

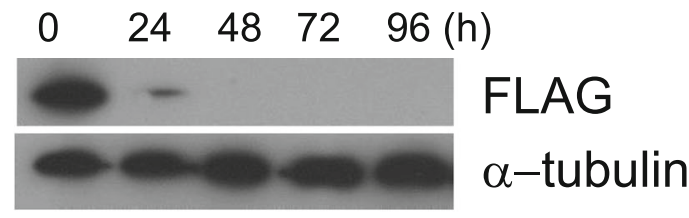

(D)

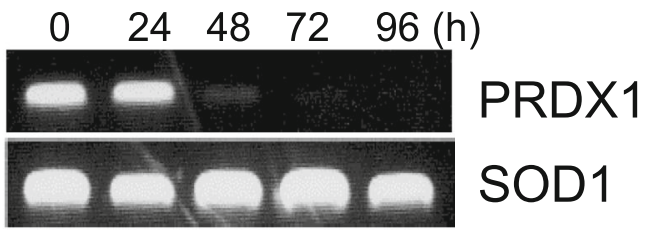

(B)

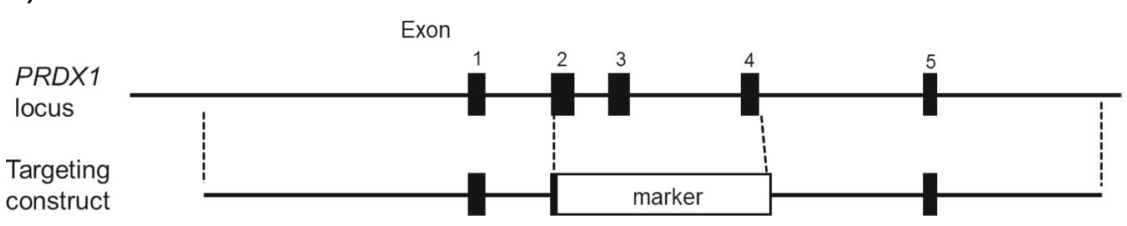

Fig. 1 Generation of PRDX1 conditional mutant cells. A Schematic representation of the PRDX1 conditional mutant of chicken DT40 cells. ggdPRDX1 cDNA was obtained by reverse transcription-PCR using mRNA from DT40 cells. DT40 wild-type cells were transfected with a plasmid expressing FLAG-tagged ggdPRDX1 ggdPRDX1 cDNA by the tet-off promoter followed by disruption of genomic PRDX1 gene. B Schematic representation of the disruption constructs. PRDX1 genomic DNA was cloned into a plasmid, and exons 2, 3, and 4 of PRDX1 were replaced with a selection marker. See Materials and Methods in details. C The Dox-dependent disappearance of chicken PRDX1 as confirmed by Western blot analysis with a-tubulin as the loading control. D The Dox-dependent disappearance of chicken PRDX1cDNA as confirmed by a RT-PCR analysis with SOD1 as the control 
PRDX1 is essential for normal cell growth and et-SH protected against cell death in PRDX1-depleted cells To elucidate the function of PRDX1, we characterized cellular phenotypes that emerged after the depletion of PRDX1. In contrast to previous finding showing that cells derived from the PRDX1 knockout mouse were viable [10, 11], PRDX1-depleted cells ceased exponential growth on the 3rd day and cell death was observed concomitant with the suppressed expression of PRDX1 after the addition of DOX (Fig. 2).

We previously reported that growth perturbations in SOD1- and SOD2-depleted cells were completely restored by the antioxidant ascorbic acid using L-ascorbic acid phosphate magnesium salt (APM) $(19,21)$. To examine the impact of various antioxidants on cell death in PRDX1-depleted cells, we compared the growth properties of cells depleted of PRDX1 in the presence of the antioxidant APM, the non-toxic dietary glutathione precursor NAC, the widely used mitochondrially targeted antioxidant 4,5-dihydroxy-1,3-benzene disulfonic acid (Tiron), and the strong reducing agent Et-SH, which reduces disulfide bonds with antioxidant capacity by scavenging hydroxyl radicals. Only Et-SH protected against cell death in PRDX1-depleted cells (Fig. 2).

\section{Et-SH suppresses overall increases in oxidative stress in PRDX1-depleted cells}

PRDXs constitute a family of thiol-dependent peroxidases that scavenge several peroxides, particularly hydrogen peroxide [1-4]. The inefficient scavenging of peroxides in PRDX1-depleted cells may result in an overall increase in oxidative stress in cells. To examine total ROS levels of in cells, we stained PRDX-depleted cells with DCFH. DCFH is a cell-permeable fluorescein dye that reacts with a broad spectrum of cellular ROS [23]. Total ROS levels were elevated in PRDX1-depleted cells (Fig. 3A). Importantly, Et-SH restored ROS to a physiological level in PRDX1-depleted cells (Fig. 3A).

Hydrogen peroxide is a secondary ROS that is generated from superoxide by SOD1 or SOD2. It is readily converted to reactive hydroxyl radicals $[25,26]$. Therefore, we investigated whether an increased amount of hydrogen peroxide is derived from superoxide. To compare cytoplasmic superoxide levels in wild-type cells and PRDX1-depleted cells, we stained cells with the highly specific fluorescent probe to superoxide, BES-So-AM [24]. As shown in Fig. 3B, superoxide levels were slightly higher in PRDX1-depleted cells than in wild-type cells. However, this slight increase in superoxide in PRDX1depleted cells did not account for the total increase in oxidative stress detected by DCFH staining (Fig. 3A). We speculate that increased ROS levels in PRDX1depleted cells were mainly due to the accumulation of peroxides.

\section{Depletion of PRDX1 does not affect genome integrity} Elevated ROS levels induce damage to cellular macromolecules, including DNA and RNA, and genomic instability, resulting in cell death. We previously reported that a chromosome integrity indicator, the frequency of

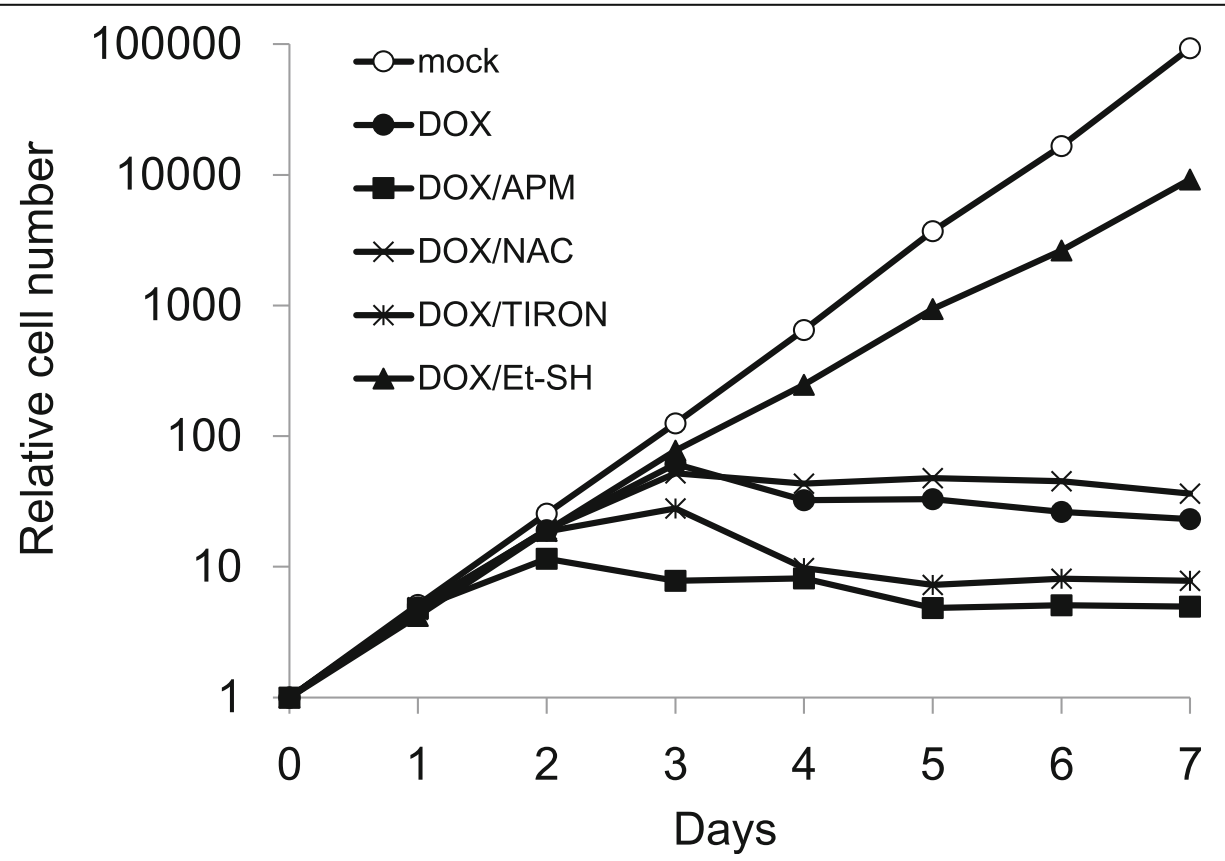

Fig. 2 Effects of antioxidants on growth profiles of PRDX1-depleted cells. Cells were incubated with or without $1 \mu \mathrm{g} / \mathrm{ml}$ Dox in the absence or presence of various antioxidants 


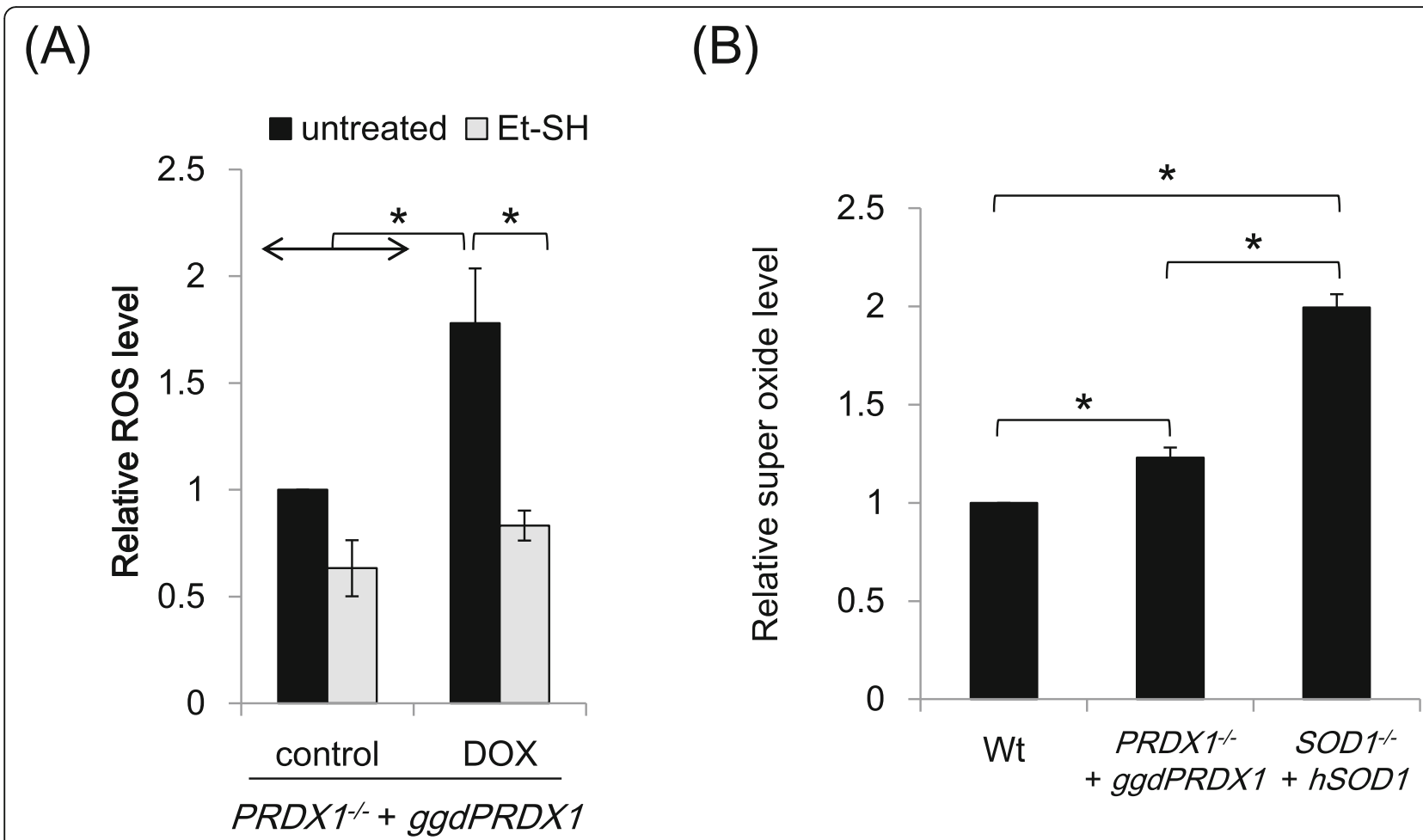

Fig. 3 Suppression of elevated cellular oxidative stress in PRDX1-depleted cells by 2-mercaptoethanol. A Total cellular oxidative stress was detected by the oxidation of the fluorescent probe DCFH. B Cytoplasmic superoxide levels in PRDX1-depleted cells. Superoxide levels were measured with BES-So-AM. Cells were treated with or without $1 \mu \mathrm{g} / \mathrm{ml}$ Dox in the absence or presence of $50 \mathrm{mM} 2$-mercaptoethanol (Et-SH) for $96 \mathrm{~h}$. SOD1-depleted cells were treated with $1 \mu \mathrm{g} / \mathrm{ml}$ Dox for $96 \mathrm{~h}$ used as a positive control in the cytoplasmic superoxide analysis (B). Data from flow cytometric analyses are shown as mean fluorescence intensity (MFI). MFI without the Dox treatment was used as the standard (arbitrary unit $=1$ ). All data represent the mean \pm standard deviation from three independent experiments. Asterisks $(*)$ indicate $p<0.05$ by a multiplecomparison one-way ANOVA (Tukey's test)

SCE with increases in oxidative stress, was approximately four-fold higher in SOD1-depleted cells than in wild-type cells [20]. To assess the impact of the depletion of PRDX1 on genomic integrity, we examined the frequency of SCE following its depletion. No significant differences were observed in the frequency of SCE between PRDX1depleted and wild-type cells (Fig. 4A). We also measured the number of chromosomal breaks, which is direct evidence of chromosomal abnormalities in cells. While chromosomal breakage was more prominent in SOD1-depleted cells, it was not induced by the depletion of PRDX1 (Fig. 4B and C). APM suppressed increased of chromosomal breakages (Fig. 4C) as well as growth perturbations in SOD1-depleted cells [21]. These results indicate that cell death in PRDX1depleted cells was not attributed to the accumulation of chromosomal damage caused by elevated ROS levels.

\section{Discussion}

PRDXs are conserved hydrogen peroxide-scavenging enzymes that also function as key regulators of multiple pathways responding to hydrogen peroxide, including molecular chaperone activity, under elevated oxidative stress as well as the transduction of redox signals [27,
28]. PRDX1 has recently emerged as a modulator of aging-dependent nutrient signaling [29]. In the present study, we demonstrated that PRDX1 was essential for normal cell growth in chicken DT40 cells. Cell death in PRDX1-deficient cells was not associated with chromosomal damage despite the accumulation of cellular ROS (due to large standard deviations in Fig. 4, we are not able to eliminate a possibility formally that PRDX1depetion causes chromosomal damage at a low level). Hydrogen peroxide acts as a signaling molecule that regulates biological processes due to its potential to induce structural alterations in proteins by preferentially oxidizing cysteine residues. The oxidation of specific amino acids in proteins that are essential for their roles in physiological processes alters their functions and activities [30]. For example, critical cysteine residues in disulfate bound in ataxia-telangiectasia mutated (ATM) can be directly oxidized and activated by a ROS-dependent, but DNA damage-independent manner [31]. We speculate that the attenuation of the fine balance between ROS production and elimination, which is maintained in a PRDX1-dependent manner, is indispensable for normal cell proliferation. 


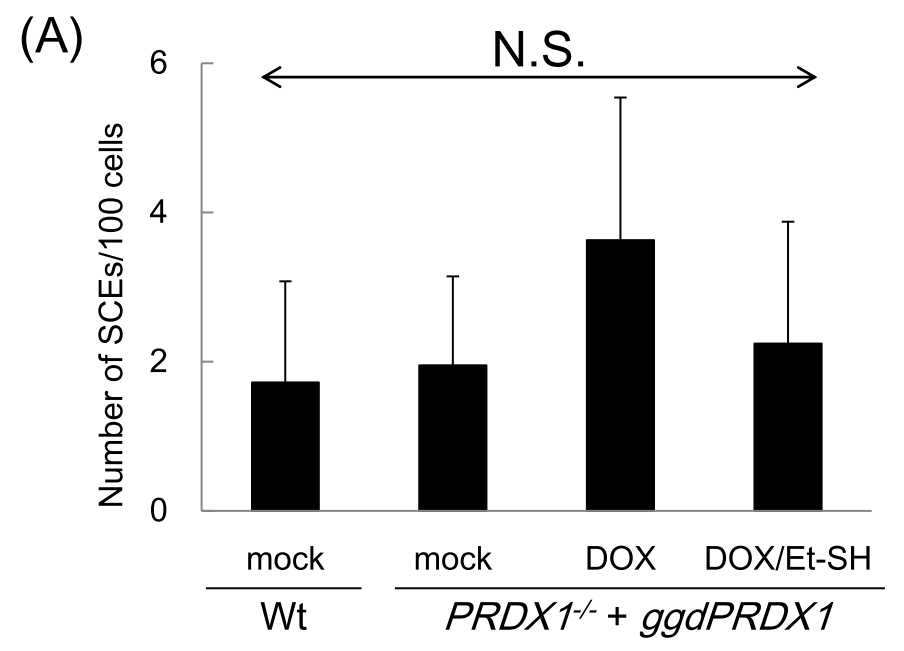

(B)

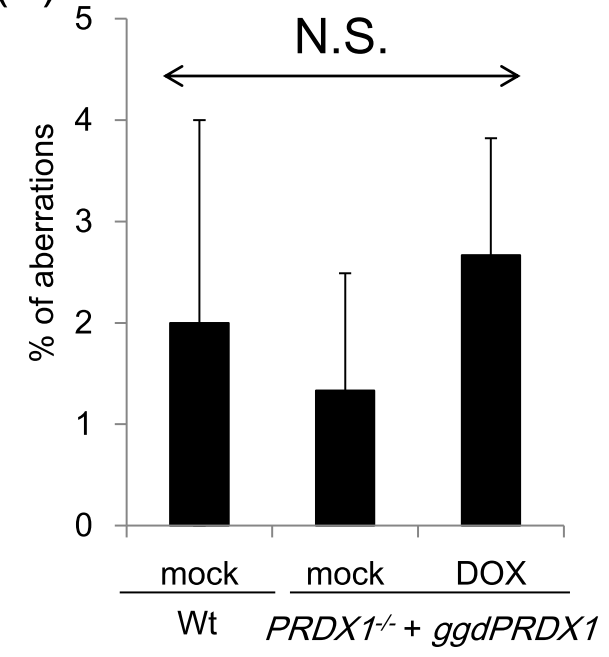

(C)

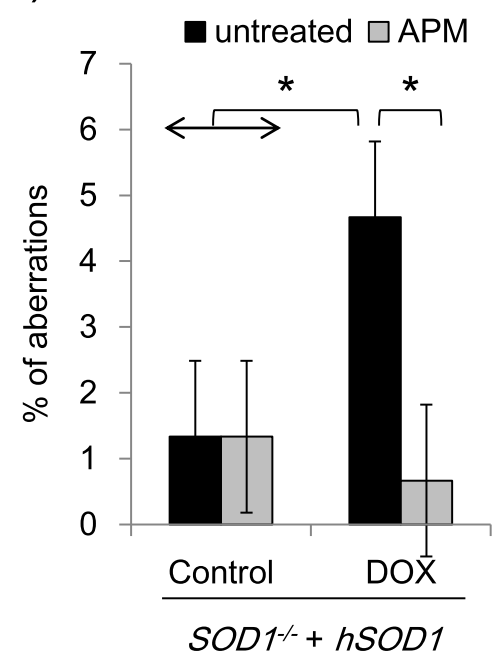

Fig. 4 PRDX1 depletion does not induce chromosomal instability. A Sister chromatid exchange (SCE). PRDX1-depleted cells were cultured in $1 \mathrm{\mu g} / \mathrm{ml}$ Dox for $96 \mathrm{~h}$ and SCE in macrochromosomes was assessed. Numbers represent the means and standard deviations of scores from 100 metaphase cells. B Chromosome aberrations. A chromosome analysis was performed with PRDX1-depleted cells. C Chromosome aberrations. A chromosome analysis of was performed with SOD1-depleated cells. SOD1-depleated cells were cultured with or without $1 \mu \mathrm{g} / \mathrm{ml}$ Dox for $96 \mathrm{~h}$ and /or ascorbic acid (APM) $200 \mu \mathrm{M}$ for $96 \mathrm{~h}$. Increase of chromosome aberrations in SOD1-depleated cells was suppressed by APM. The number of chromosome aberrations per 50 metaphase nuclei from the indicated cells was counted. All data represent the mean \pm standard deviation from three independent experiments. Asterisks $\left(^{*}\right)$ indicate $p<0.05$ by a multiple-comparison one-way ANOVA (Tukey's test), and N.S. indicates not significant $(p \geq 0.05)$

We previous reported that mitochondrial SOD2depleted cells showed growth perturbations without chromosomal aberrations [19]. We also reported that increased ROS in concomitant with growth perturbation in SOD2-depleted cells were rescued by APM, but not by Et-SH [21]. These results suggested that the perturbation of ROS levels in mitochondria induces cell death without generating chromosomal damage, and APM might scavenge different species of ROS from Et-SH. However, we cannot eliminate the possibility that ROSinduced DNA damage in mitochondrial DNA causes cell death in PRDX1-depleted cells. Among the 6 PRDX family genes reported in vertebrates, PRDX5, which contains the mitochondrial targeting sequence, is absent in the aves genome $[32,33]$. Aves PRDX1 localizes to the cytosol but may have an unknown role in the maintenance of mitochondrial ROS for proper cell growth.

A previous study showed that PRDX1 knockout mice developed severe hemolytic anemia and several malignant cancers, including lymphomas, which shortened their life span [10]. The DT40 chicken B-cell line used in the present study is derived from an ALV-induced 
bursal lymphoma. We speculate that B cell-derived DT40 cells require a lymphoblastic cell-specific cellular environment, which increases susceptibility to the damaging effects of excessive ROS levels.

\section{Conclusions}

In the present study, we demonstrated the critical role of PRDX1 in ROS homeostasis for cell viability. However, the mechanisms underlying the PRDX1-mediated regulation of ROS homeostasis have not yet been elucidated in detail. We found that cell death and the accumulation of ROS in PRDX1-deficient cells were suppressed by EtSH (Fig. 2). Further investigations are needed to clarify the mechanisms by which cell death and ROS production are suppressed by Et-SH. Our strategy to systematically generate a conditional antioxidant gene mutant in DT40, particularly PRDX1-depleted cells, will become a powerful tool for examining the maintenance of ROS in normal physiological processes.

\section{Abbreviations}

ALV: Avian leukosis virus; APM: L-ascorbic acid phosphate magnesium salt; ATM: Ataxia-telangiectasia mutated; DCFH-DA: 2',7'dichlorodihydrofluorescein diacetate; Dox: Doxycycline; Et-SH: 2mercaptoethanol; ggdPRDX1: Gallus gallus domesticus PRDX1; PRDX1: Peroxiredoxin 1; ROS: Reactive oxygen species; RT-PCR: Reverse transcription-PCR; SCE: Sister chromatid exchange; SOD1: Superoxide dismutase 1; SOD2: Superoxide dismutase 2; Tiron: 4,5-dihydroxy-1,3-benzene disulfonic acid

\section{Acknowledgements}

Authors thank Dr. Tadayoshi Bessho for his critical reading of this manuscript and Dr. Eri Inoue and Ms. Saki Okamoto for their excellent technical assistance.

\section{Authors' contributions}

$K T$, MS designed the project and performed the experiments, data analysis and drafted the manuscript. TM, AY. contributed equally. AY designed KO strategy and made conditional KO cells. TM designed and performed the cell growth and fluorescent analysis and statical analysis. TY performed the fluorescent experiments. SH, ST gave valuable indication and helped design the experiments. All authors approved final manuscript.

\section{Funding}

This study was supported by JSPS KAKENHI grant numbers 18 K11640 to KT.

\section{Availability of data and materials}

All data generated or analyzed during this study are included in this published article.

\section{Declarations}

Ethics approval and consent to participate

Not applicable.

\section{Consent for publication}

Not applicable.

\section{Competing interests}

The authors declare that they have no competing interests.

\section{Author details}

'Department of Molecular and Genetic Medicine, Kawasaki Medical School, 577, Matsushima, Kurashiki-city, Okayama 701-0192, Japan. ²Division of Biochemistry, Faculty of Pharmaceutical Sciences, Tohoku Medical and
Pharmaceutical University, 4-4-1 Komatsushima, Aoba-ku, Sendai, Miyagi 981-8558, Japan. ${ }^{3}$ Department of Radiology, Kyoto Prefectural University of Medicine, Kajii-cho, Kawaramachi-Hirokoji,Kamigyo-ku, Kyoto 602-8566, Japan. ${ }^{4}$ Department of Radiation Genetics, Graduate School of Medicine, Faculty of Medicine, Kyoto University, Yoshida-Konoe-cho, Sakyo-ku, Kyoto 606-8501, Japan. ${ }^{5}$ Department of Biological Sciences, Graduate School of Science, Osaka Prefecture University, 1-1 Gakuen-cho, Naka-ku, Sakai, Osaka 599-8531, Japan.

Received: 5 May 2021 Accepted: 26 July 2021

Published online: 05 August 2021

\section{References}

1. Bryk R, Griffin P, Nathan C. Peroxynitrite reductase activity of bacterial peroxiredoxins. Nature. 2000;407:211-5.

2. Rhee SG, Kang SW, Chang TS, Jeong W, Kim K. Peroxiredoxin, a novel family of peroxidases. IUBMB Life. 2001;52(1):35-41. https://doi.org/10.1080/1521 6540252774748.

3. Wood ZA, Schröder E, Harris JR, Poole LB. Structure, mechanism and regulation of peroxiredoxins. Trends Biochem Sci. 2003;28(1):32-40. https:// doi.org/10.1016/50968-0004(02)00003-8.

4. Rhee SG. Overview on Peroxiredoxin. Mol Cell. 2016;39(1):1-5. https://doi. org/10.14348/molcells.2016.2368.

5. Knoops B, Loumaye E, Van Der Eecken V. Evolution of the peroxiredoxins. Subcell Biochem. 2007;44:27-40. https://doi.org/10.1007/978-1-4020-605192.

6. Hall A, Nelson K, Poole LB, Karplus PA. Structure-based insights into the catalytic power and conformational dexterity of peroxiredoxins. Antioxid Redox Signal. 2011;15(3):795-815. https://doi.org/10.1089/ars.2010.3624.

7. Hirotsu S, Abe Y, Okada K, Nagahara N, Hori H, Nishino T, et al. Crystal structure of a multifunctional 2-Cys peroxiredoxin heme-binding protein 23 $\mathrm{kDa} /$ proliferation-associated gene product. Proc Natl Acad Sci U S A. 1999; 96(22):12333-8. https://doi.org/10.1073/pnas.96.22.12333.

8. Rhee SG, Kang SW, Jeong W, Chang TS, Yang KS, Woo HA. Intracellular messenger function of hydrogen peroxide and its regulation by peroxiredoxins. Curr Opin Cell Biol. 2005;17(2):183-9. https://doi.org/10.101 6/.j.ceb.2005.02.004.

9. Chae HZ, Kim HJ, Kang SW, Rhee SG. Characterization of three isoforms of mammalian peroxiredoxin that reduce peroxides in the presence of thioredoxin. Diabetes Res Clin Pract. 1999;45(2-3):101-12. https://doi.org/10.1 016/50168-8227(99)00037-6.

10. Neumann CA, Krause DS, Carman CV, Das S, Dubey DP, Abraham JL, et al. Essential role for the peroxiredoxin Prdx1 in erythrocyte antioxidant defense and tumor suppression. Nature. 2003;424(6948):561-5. https://doi.org/10.103 8/nature01819.

11. Egler RA, Fernandes E, Rothermund K, Sereika S, de Souza-Pinto N, Jaruga P, et al. Regulation of reactive oxygen species, DNA damage, and c-Myc function by peroxiredoxin1. Oncogene. 2005;24(54):8038-50. https://doi. org/10.1038/sj.onc.1208821.

12. Cao J, Schulte J, Knight A, Leslie NR, Zagozdzon A, Bronson R, et al. Prdx1 inhibits tumorigenesis via regulating PTEN/AKT activity. EMBO J. 2009;28: 15051-1517.

13. Jezierska-Drutel A, Attaran S, Hopkins BL, Skoko JJ, Rosenzweig S, Neumann CA. The peroxidase PRDX1 inhibits the activated phenotype in mammary fibroblasts through regulating C-Jun N-terminal kinases. BMC Cancer. 2019; 19(1):812. https://doi.org/10.1186/s12885-019-6031-4.

14. Ito T, Kimura S, Seto K, Warabi E, Kawachi Y, Shoda J, et al. Et al. Peroxiredoxin I plays a protective role against UVA irradiation through reduction of oxidative stress. J Dermatol Sci. 2014;74(1):9-17. https://doi. org/10.1016/j.jdermsci.2013.12.002.

15. Guo W, Liu X, Li J, Shen Y, Zhou Z, Wang M, et al. Prdx1 alleviates cardiomyocyte apoptosis through ROS-activated MAPK pathway during myocardial ischemia/reperfusion injury. Int J Biol Macromol. 2018;112:60815. https://doi.org/10.1016/j.jijbiomac.2018.02.009.

16. Liu Q, Zhang Y. PRDX1 enhances cerebral ischemia-reperfusion injury through activation of TLR4-regulated inflammation and apoptosis. Biochem Biophys Res Commun. 2019;519(3):453-61. https://doi.org/10.1016/j.bbrc.201 9.08.077.

17. Jang HH, Kim SY, Park SK, Jeon HS, Lee YM, Jun JH, et al. Phosphorylation and concomitant structural changes in human 2-Cys peroxiredoxin isotype I 
differentially regulate its peroxidase and molecular chaperone functions. FEBS Lett. 2006;580(1):351-5. https://doi.org/10.1016/j.febslet.2005.12.030

18. Nassour H, Wang Z, Saad A, Papaluca A, Brosseau N, Affar EB, et al. Peroxiredoxin 1 interacts with and blocks the redox factor APE1 from activating interleukin-8 expression. Sci Rep. 2016;6(1):29389. https://doi.org/1 $0.1038 /$ srep29389

19. Takada S, Inoue E, Tano K, Yoshii H, Abe T, Yoshimura A, et al. Generation and characterization of cells that can be conditionally depleted if mitochondrial SOD2. Biohem Biophys Res Commun. 2009;379(2):233-8. https://doi.org/10.1016/j.bbrc.2008.12.031.

20. Inoue $\mathrm{E}$, Tano K, Yoshii H, Nakamura J, Tada S, Watanabe M, et al. SOD1 is essential for the viability of DT40 cells and nuclear SOD1 functions as a guardian of genomic DNA. J Nucleic Acid. 2010;795946. https://doi.org/10.4 061/2010/795946.

21. Tamari Y, Nawata $H$, Inoue E, Yoshimura A, Yoshii H, Kashino G, et al. Protective roles of ascorbic acid in oxidative stress induced by depletion of superoxide dismutase in vertebrate cells. Free Radic Res. 2013;47(1):1-7. https://doi.org/10.3109/10715762.2012.734916.

22. Sonoda E, Sasaki MS, Buerstedde JM, Bezzubova O, Shinohara A, Ogawa $\mathrm{H}$, et al. Rad51-deficient vertebrate cells accumulate chromosomal breaks prior to cell death. EMBO J. 1998;17(2):598-608. https://doi.org/10.1093/emboj/1 7.2.598.

23. Yohii $\mathrm{H}$, Watanabe $\mathrm{M}$. Intervention of oxygen-control ability to radiation sensitivity, cell aging and cell transformation. J Radiat Res. 2009;50(2):12737. https://doi.org/10.1269/jrr.08088.

24. Maeda H, Yamamoto K, Kohno I, Hafsi L, Nakagawa S, Kanagawa N, et al. Design of a practical fluorescent probe for superoxide based on protection deprotection chemistry of fluorescein with benzene sulfonyl protecting groups. Chemistry. 2007;13(7):1946-54. https://doi.org/10.1002/chem.2 00600522.

25. Nordberg J, Arnér ESJ. Reactive oxygen species, antioxidants, and the mammalian thioredoxin system. Free Radic Biol Med. 2001;31:1287-312.

26. Li J-M. ShahAM, endothelial cell superoxide generation: regulation and relevance for cardiovascular pathophysiology. Am J Phys. 2004;287:R101430.

27. D'Autre'aux B, Toledano MB. ROS as signaling molecules: mechanisms that generate specificity in ROS homeostasis. Nat Rev Mol Cell Biol. 2007;8:81324.

28. Molin M, Demir AB. Linking peroxiredoxin and vacuolar-ATPase functions in calorie restriction-mediated life span extension. Int J Cell Biol. 2014;913071: $1-12$.

29. Nyström T, Yang J, Molin M. Peroxiredoxins, gerontogenes linking aging to genome instability and cancer. Genes Dev. 2012;26:2001-8.

30. Rhee SG. $\mathrm{H}_{2} \mathrm{O}_{2}$, a necessary evil for cell signaling. Science. 2006;312(5782): 1882-3. https://doi.org/10.1126/science.1130481.

31. Guo Z, Kozlov S, Lavin MF, Person MD, Tanya, Paull TT. ATM activation by oxidative stress. Science. 2010;330(6003):517-21. https://doi.org/10.1126/ science.1192912.

32. Han JY, Song KD, Shin JH, Han BK, Park TS, Park HJ, et al. Identification and characterization of the peroxiredoxin gene family in chickens. Poult Sci. 2005;84(9):1432-8. https://doi.org/10.1093/ps/84.9.1432.

33. Pirson M, Clippe A, Knoopsv B. The curious case of peroxiredoxin-5: what its absence in avens can tell us and how it can be used. BMC Evol Biol. 2018; 18(1):18. https://doi.org/10.1186/s12862-018-1135-z.

\section{Publisher's Note}

Springer Nature remains neutral with regard to jurisdictional claims in published maps and institutional affiliations.

Ready to submit your research? Choose BMC and benefit from:

- fast, convenient online submission

- thorough peer review by experienced researchers in your field

- rapid publication on acceptance

- support for research data, including large and complex data types

- gold Open Access which fosters wider collaboration and increased citations

- maximum visibility for your research: over $100 \mathrm{M}$ website views per year

At BMC, research is always in progress.

Learn more biomedcentral.com/submissions 